\title{
Accounting Data Quality Evaluation Method Based on Improved Particle Swarm Algorithm
}

\author{
Mengying Sun \\ Xinyang Vocational and Technical College Business School, Xinyang 464000, China \\ Correspondence should be addressed to Mengying Sun; sunmengying2021@xyvtc.edu.cn
}

Received 28 November 2021; Revised 20 December 2021; Accepted 27 December 2021; Published 20 January 2022

Academic Editor: Qiangyi Li

Copyright (c) 2022 Mengying Sun. This is an open access article distributed under the Creative Commons Attribution License, which permits unrestricted use, distribution, and reproduction in any medium, provided the original work is properly cited.

\begin{abstract}
With the continuous improvement of the capital market and related laws and regulations, accounting as a reflection of the corporate capital movement will have a significant impact on the quality of the entire accounting information. Moreover, for investors, whether accounting information can meet their needs is an important basis for assessing the feasibility of investment projects. Therefore, the importance of accounting information is becoming more and more important, and it has gradually become the focus of attention of all parties. In order to improve the effect of accounting quantity and quality evaluation, this article improves the particle swarm optimization algorithm. It improves the particle swarm optimization algorithm from the three aspects-extreme value selection, particle diversity, and inertia weight, and establishes an optimization algorithm suitable for solving the accounting data audit optimization problem. The experimental research results show that the accounting data quality evaluation system based on the improved particle swarm algorithm proposed in this article has a good accounting data quality evaluation effect and meets the basic requirements of this article to build the system.
\end{abstract}

\section{Introduction}

Although there have been many results in the research on corporate financing constraints, no one has studied whether the dual effects of accounting information quality and internal control will have a positive impact on financing constraints. It is of great theoretical significance to enrich the research on the factors affecting financing constraints and to promote the sustainable and healthy development of the company. First, it enriches the research on corporate financing constraints. Previous studies at home and abroad mainly focused on taxation policies, financial development, asset mortgage ability, and other external formal systems and corporate social responsibility disclosure perspectives to study their impact on financing constraints [1]. Based on the perspective of the joint action of internal factors and external factors, the research on the impact of corporate financing constraints has improved the research in the field of financing constraints. Furthermore, from the existing theoretical research, most of the literature mainly studies the role of financing constraints in terms of the robustness, prudence, and reliability of accounting information. Although these characteristics are the core of accounting information, there is no comprehensive study on the relationship between the quality of accounting information and financing constraints [2]. In addition, internal control is an important normative system for enterprises, but few people have studied the influence of internal control on financing constraints. Moreover, in the rare research on the constraints of internal control on corporate financing, there is less connection between the quality of accounting information and internal control. Moreover, in the current research on financing constraints, scholars pay more attention to the impact of unilateral factors and seldom consider the impact of multiple factors [3].

Based on the actual needs of accounting data quality evaluation, this article combines the improved particle swarm algorithm to study the accounting data quality 
evaluation method, builds an intelligent analysis model based on the actual situation, and further improves the evaluation effect of accounting data quality on this basis.

\section{Related Work}

Foreign scholars have studied the impact of accounting information on financing constraints from the perspective of corporate financing costs. Literature [4] introduces the theory of information asymmetry into the capital market and believes that the existence of information asymmetry causes investors to increase the external financing costs of enterprises, leading to the differentiation of internal and external financing costs. Literature [5] based on the connection of the quality of information disclosure, the study found that the more reliable and prudent accounting information companies tend to gain more trust and support from investors and generally provide higher prices, thereby reducing the cost of equity financing. Literature [6] focuses on how creditors will choose when facing companies with different accounting information quality. Relatively speaking, corporate owners with poor accounting information disclosure generally consider risk factors such as debt recovery, so they will require certain. The risk premium is compensated, thereby increasing the difficulty of corporate financing. Literature [7] found that when investors are at an information disadvantage, they often use the accounting information disclosed by the company to understand the financial status and operating status of the company, and high-quality accounting information will give investors more authentic and reliable information, and information, which will reduce the financing cost caused by the risk premium. In addition, there are also information asymmetries between different investors, which may cause "adverse selection" problems. Therefore, improving the quality of accounting information can also reduce the financing costs caused by adverse selection.

In Literature [8], after controlling the company's scale and financial risk factors, the empirical results show that when companies disclose high-quality accounting information, the lower the cost of capital they face, the more significant the impact in the communications industry. Listed companies and market regulators provide a better basis for decision-making. Literature [9] found that the higher the quality of social responsibility information disclosure, the lower the degree of financing constraints. It is further found that the disclosure of social responsibility information by companies can help with equity refinancing, reduce financing costs, and ease financing constraints. Literature [10], based on two types of accounting conservatism perspectives, empirically found that accounting conservatism is significantly negatively correlated with financing constraints. Further research found that unconditional conservatism is more helpful than conditional conservatism to alleviate the degree of financing constraints, and accounting conservatism as an important feature of accounting information quality has a very good enlightening effect on improving the quality of accounting information and alleviating financing constraints. Chessell and Negurita [11] added the variable of accounting information quality on the basis of studying the relationship between company-specific risks and corporate financing constraints and found that company-specific risks and financing constraints are significantly positively correlated; that is, the greater the risk a company faces, the more difficult it is to finance. This relationship is particularly obvious among small- and medium-sized enterprises. However, companies that disclose high-quality accounting information will weaken the positive correlation between the two, indicating that improving the quality of accounting information can help reduce information gaps. The degree of symmetry reduces financing costs. Based on the theory of information asymmetry, literature [12] studied the impact of accounting information on the financing constraints of listed companies from the perspectives of accounting earnings quality and accounting information transparency, and found that the higher the quality of accounting earnings, the lower the degree of financing constraints faced by the company. The increase in the transparency of accounting information has a deeper impact on the financing constraints of non-state-owned enterprises.

Literature [13] found that the recognition of the company's internal control report will have an impact on the earnings quality. When the review agency issues an unfavorable opinion on the company's internal control report, it will affect the company's earnings quality for the next year, showing a significant downward trend. On the contrary, When the review agency approved the internal control report of a company, it showed a significant upward trend compared with the previous year. From the perspective of market response, literature [14] found that companies with a relatively complete internal control system would respond positively to the market, whereas companies with internal control defects would respond negatively to the market, and there was a positive correlation between the two. Literature [15] found a positive correlation between the severity of internal control problems and audit fees through a large amount of data collection. Literature [16] found that companies with more complete internal control systems have higher investment efficiency from the perspective of investment, whereas companies with incomplete internal control systems will have an adverse effect on investment efficiency, but they can improve investment efficiency by establishing and improving internal control systems. Literature [17] empirically studied the impact of internal control defects on inventory management and found that in companies with larger internal control defects, the greater the inventory impairment loss, the lower the turnover rate.

\section{Improved Particle Swarm Algorithm}

MOP refers to the optimization model with more than one objective function and is hoped to obtain the best optimization problem as much as possible at the same time, as follows [18]: 


$$
\begin{cases}\min & Y=F(X)=\left(f_{1}(X), f_{2}(X), \ldots, f_{n}(X)\right) \quad n=1,2, \ldots, N, \\ & g_{i}(x) \leq 0, \quad i=1,2,3, \ldots, m, \\ & h_{j}(x)=0, \quad j=1,2, \ldots, k \\ & X=\left[x_{1}, x_{2}, \ldots, x_{d}, \ldots, x_{d}\right] \\ & x_{d_{-} \min } \leq x_{d} \leq x_{d_{-} \max }, \quad d=1,2, \ldots, D\end{cases}
$$

where $\mathrm{X}$ is the $\mathrm{D}$-dimensional decision vector; $\mathrm{Y}$ is the target vector; and $\mathrm{N}$ is the total number of optimization targets.

Corresponding to the mathematical definition of asymmetric steering mechanism, it is given as

$\begin{cases}\min & F(X)=\left(f_{3}(X), f_{4}(X)\right), \\ \text { s.t } & \text { Simultaneously meet (3.25). (3.28), (3.30), (3.32). }\end{cases}$

For any $\mathrm{d} \in[1, \mathrm{D}]$, if $\mathrm{X}^{*}{ }_{\mathrm{d}} \leq X_{\mathrm{d}}$ and $d_{0} \in[1, D]$ satisfies $x_{d_{0}}^{*}<x_{d_{0}}$, then vector $X^{*}=\left[X_{1}^{*}, X_{2}^{*}, \ldots, X_{D}^{*}\right]$ dominates vector $X^{*}=\left[X_{1}, X_{2}, \ldots, X_{d}\right]$. When $f\left(x^{*}\right)$ dominates $f(x)$, the following two conditions must be met [19]:

$$
\begin{aligned}
\forall n f_{n}(X *) \leq f_{n}(x), & n=1,2, \ldots, N \\
\exists f_{n_{0}} f_{n_{0}}\left(X^{*}\right)<f_{n}(X), & 1 \leq n_{0} \leq N .
\end{aligned}
$$

The position and velocity of each particle are updated as follows [20]:

$$
\begin{aligned}
& X_{i, d}(t+1)=X_{i, d}(t) V_{i, d}(t+1) \\
& V_{i d}(t+1)=\omega V_{i d}(t)+c_{1} r_{1}\left(P_{i, d}(t)\right)+c_{2} r_{2}\left(P_{g, d}(t)\right) .
\end{aligned}
$$

According to the above steps, the flowchart of the standard PSO algorithm is shown in Figure 1 [21].

This article mainly applies the improved particle algorithm to the assessment of accounting data quality, so it is necessary to analyze the accounting information theory. The information asymmetry theory refers to the different levels of knowledge of certain information among entities in market economic activities and the degree of understanding of the information. The clearer and clearer the subject is, the greater the advantage is. The existence of information asymmetry will make it difficult for the principal to conduct a reasonable examination of the agent with whom he is in a principal-agent relationship, but the agent can use the advantage of information asymmetry to seek the greatest benefit for himself. Information asymmetry will produce adverse selection, because the party who has a more comprehensive understanding of information will use its advantage to harm the interests of the other party who does not understand the information and then produce the phenomenon of "bad money drives out good money." Information asymmetry will also increase moral hazard. In order to maximize their own interests, the information-superior party harms the interests of the information-inferior party. The theory of information asymmetry is widely used in the field of auditing. The departmental budget execution audit under the full coverage of the audit is to centrally aggregate the business data and accounting data of multiple audited units to realize the association and data of multiple business systems. In contrast, through data analysis, it is found that the budget execution does not conform to the relevant financial system norms. In this case, the original method of obtaining basic accounting information of accounting data through inquiry under the on-site audit is no longer feasible in the case of centralized analysis of the full-coverage data of the audit, which increases the asymmetry of information. Therefore, it is necessary to evaluate the quality of government accounting data, find out the units with poor data, and make rectifications, so as to reduce the audit risk caused by the asymmetry of audit information.

The reason lies in the essential difference between the two. The solution obtained by a multi-objective optimization problem is usually a set of one or several sets of continuous solutions. But the PSO algorithm and the genetic algorithm are still very different. In the genetic algorithm, sharing information between chromosomes is that the entire group gradually moves to a good area, wherein the PSO algorithm, the information is given by the best particles, and other individuals follow the best particles to quickly converge to a point. Therefore, this article directly uses the PSO algorithm to deal with the multi-objective optimization problem, which will easily converge to the local area of the nondominated optimal domain. The improved multi-objective particle swarm optimization (IMPSO) algorithm is to improve the selection of extreme values, the diversity of particles, and the inertia weight that affects the particle swarm algorithm, thereby improving the reliability and efficiency of the algorithm.

3.1. Extremum Selection Strategy. The multi-objective particle swarm algorithm in this article adopts the elite archiving strategy in the genetic algorithm. The order value of the particles is used to measure the degree of dominance of each particle in the corresponding target vector. In the first iteration, if the target vector of the individual $X$ is dominated by the target vector of the individual in $\mathrm{P}$, then the order value of the individual $X$ is $\operatorname{rank}\left(X_{i}, t\right)$, and the initial value of the individual order value is set to 1 . Therefore, the smaller the order value, the smaller the degree of dominance of the particle, and the better the target vector of the particle. Conversely, the larger the order value, the worse the particle's target vector. In this article, an archive is set up outside the population, and an elite archiving operation is adopted to save individuals with a smaller order value to the external archive. When the particle velocity is updated, all the required extreme values are directly selected randomly from the external archive. For the selection of individual 


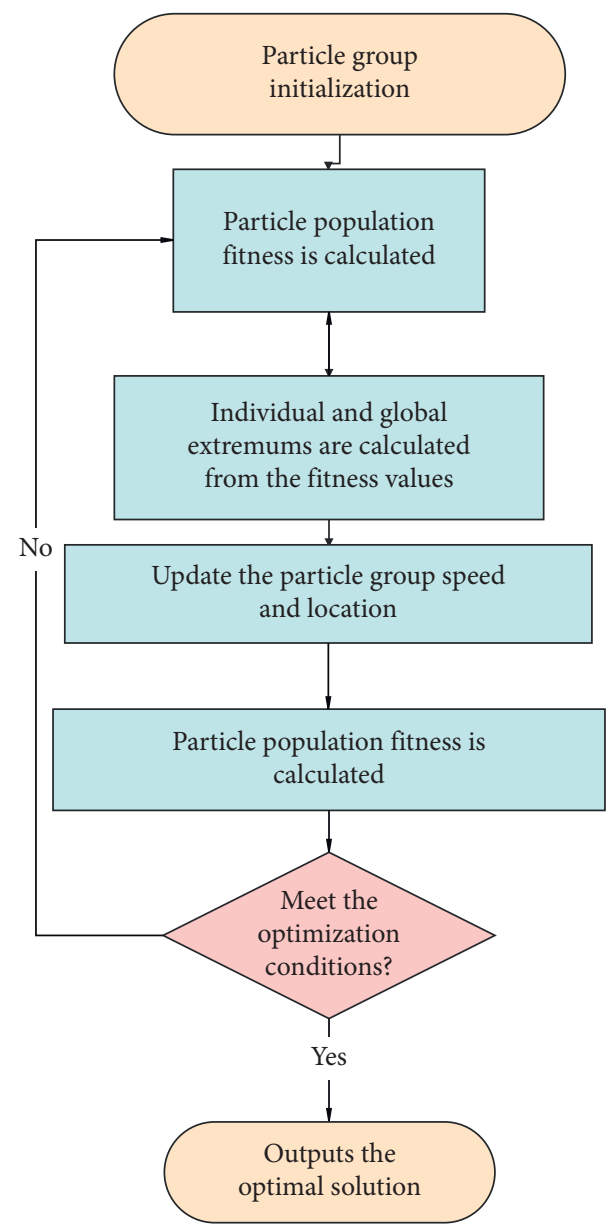

FIGURE 1: Flowchart of the standard particle swarm optimization algorithm.

extremum, a nondominated solution is selected as the individual extremum of the particle from the current position of the particle and the historical optimal position. If the two are not dominated, the individual optimal value is kept unchanged.

3.2. Line Density Deletion Strategy. $P_{s}=\left[X_{1}, X_{2}, \ldots, X_{M}\right]$ is the nondominated solution set in the external archives of the population when a certain algorithm evolves to the first generation, and $P_{F}=\left[F\left(X_{1}\right), F\left(X_{2}\right), \ldots F\left(X_{M}\right)\right]$ is the target vector set corresponding to the nondominated solution. Then, the linear density of the non-dominated solution and the average linear density of the nondominated solution set are defined as follows:

$$
\begin{aligned}
\rho_{i} & =\frac{d_{i}}{L}, \quad(i=1,2, \ldots m), \\
\bar{\rho}_{i} & =\frac{\sum_{i}^{m} \rho_{i}}{m} \\
d_{i} & =\min _{j \in i, j \neq i}\left(\sqrt{\left[f_{1}\left(X_{i}\right)-f_{1}\left(X_{j}\right)\right]^{2}+\cdots+\left[f_{n}\left(X_{i}\right)-f_{n}\left(X_{j}\right)\right]^{2}}\right), i, \quad j=1,2, \ldots m, \\
L & =\sum_{i=1}^{m} d_{i}^{*} .
\end{aligned}
$$


where $m$ is the number of nondominated solutions, $n$ is the number of objective functions, and pi is the linear density of nondominated solutions. It can be seen that the smaller the linear density pi, the smaller the distance between the target values of the nondominated solutions, and the denser the nondominated solutions there. Conversely, the smaller the pi, the more dispersed the nondominated solutions. By deleting the dense nondominated solutions, the diversity of the nondominated solutions can be increased.
3.3. Inertial Weight Adjustment Strategy. The inertial weight value $a$ is used to control the influence of historical velocity on the current velocity of particles and can balance the global detection and local detection of the group. If the inertia weight is larger, it is more favorable for global detection. On the contrary, smaller is conducive to local in-depth detection. On the contrary, smaller is conducive to local in-depth detection. A calculation strategy of inertia weight is proposed:

$$
\omega(i)=f * \operatorname{avg}\left\{\begin{array}{l}
\omega(i)-\left(\omega\left(i-\omega_{\min }\right) \times\left|\frac{f_{i}-f *_{\text {avg }}}{f_{m}-f *_{\text {avg }}}\right| \text { iff }_{i}<f *_{\text {avg }},\right. \\
\omega(i) \text { iff } *_{\text {avg }}<f_{i}<f *_{\text {avg }}, \\
1.4-\frac{1}{1+k_{1} \exp \left(-k_{2} \triangle\right)} \text { iff }_{i}>f_{\text {ave }},
\end{array}\right.
$$

where $f_{i}$ is the fitness value of the $\mathrm{i}$-th particle, $f *_{\text {avg }}$ is the fitness value of the optimal particle value, $f *_{\text {avg }}$ is the average fitness value of the particle swarm, and $f *$ avg is the average fitness value of all particles whose fitness value is better than $f_{\text {ave }}, \Delta=\left|f_{m}-f *_{\text {avg }}\right|$. The smaller the $\Delta$, the easier it is for the particle swarm to converge prematurely, and the value of each parameter is $\omega_{\min }=0.4, k_{1}=1.5, k_{2}=0.3_{\circ}$.

\section{Accounting Data Quality Evaluation Based on Improved Particle Swarm Algorithm}

Accounting software can be divided into discrete application mode and centralized application mode according to whether the unit is centralized or not: discrete application mode, that is, traditional administrative institutions purchase software separately. For example, the most common software is UFIDA U8, and the unit accountant fully masters the configuration, data storage, and management of accounting software. This is a relatively traditional software application method. It depends on the unit's internal control level and the quality of accounting personnel; the centralized application model has been a new government accounting application model in recent years. The accounting software of administrative institutions is uniformly configured and applied by the higher-level supervisory unit, and some are coordinated by the software of the industry supervisory department. Some are coordinated by the business departments of financial institutions. Under the centralized application mode, unified requirements will be made for the application of accounting software, and the standardization has been greatly improved. From the perspective of the use of accounting software functions, whether the software's auxiliary accounting is scientific and effective will greatly affect the completeness and comparability of accounting data. Auxiliary accounting uses accounting subjects as the carrier to provide a more comprehensive supplementary reflection of economic transactions involving income, expenditure, and exchange payments. When accounting for a business, in addition to the subsidiary ledger and general ledger, it also needs to be recorded in the auxiliary accounting book. The following takes expenditures as an example to describe the influence of accounting title setting on the degree of accounting standardization of government units.

Audit data quality is the basic theoretical issue of databased auditing. Research on audit data quality is of great significance to the development and improvement of computer-assisted audit theory and practice. At present, the research on audit data quality in Chinese academic circles and practice departments has just begun, and a systematic theory has not yet been formed, nor has an exact definition of audit data quality been given. Therefore, referring to the description of data quality mentioned above, from a qualitative point of view, we will use a set of reasonable evaluation indicators to represent the characteristics of audit data quality (Figure 2).

To control the quality of audit data from the entire life cycle of data generation, the general process of online audit should first be analyzed. The basic process of online audit can still be divided into three stages: audit preparation, audit implementation, and audit termination stage. However, in each link of each stage, the content and focus of the audit work have changed; especially, the electronic data process is playing an increasingly important role in the audit work. The implementation of online auditing is mainly accomplished through key steps such as data collection, data conversion, and analysis and processing. Therefore, the control content of audit data quality has also shifted in various links. By analyzing the online audit process, we will discuss how to ensure and improve data quality from a technical perspective, as shown in Figure 3.

Accounting goal is the basic quality requirement that accounting information should meet, and it is the rigid 


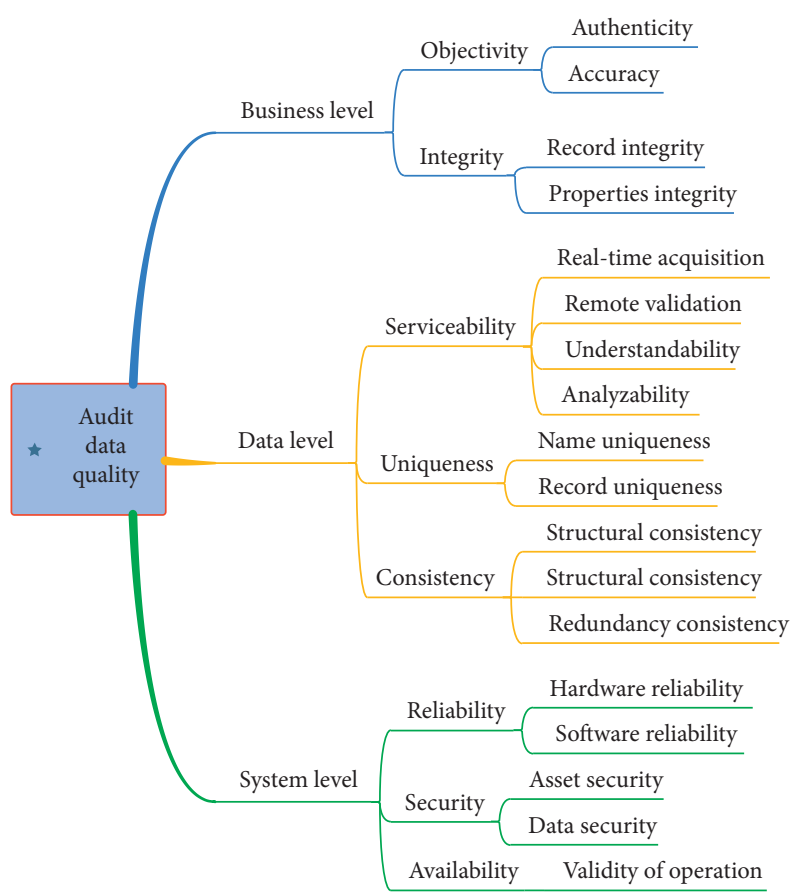

Figure 2: Audit data quality diagram.

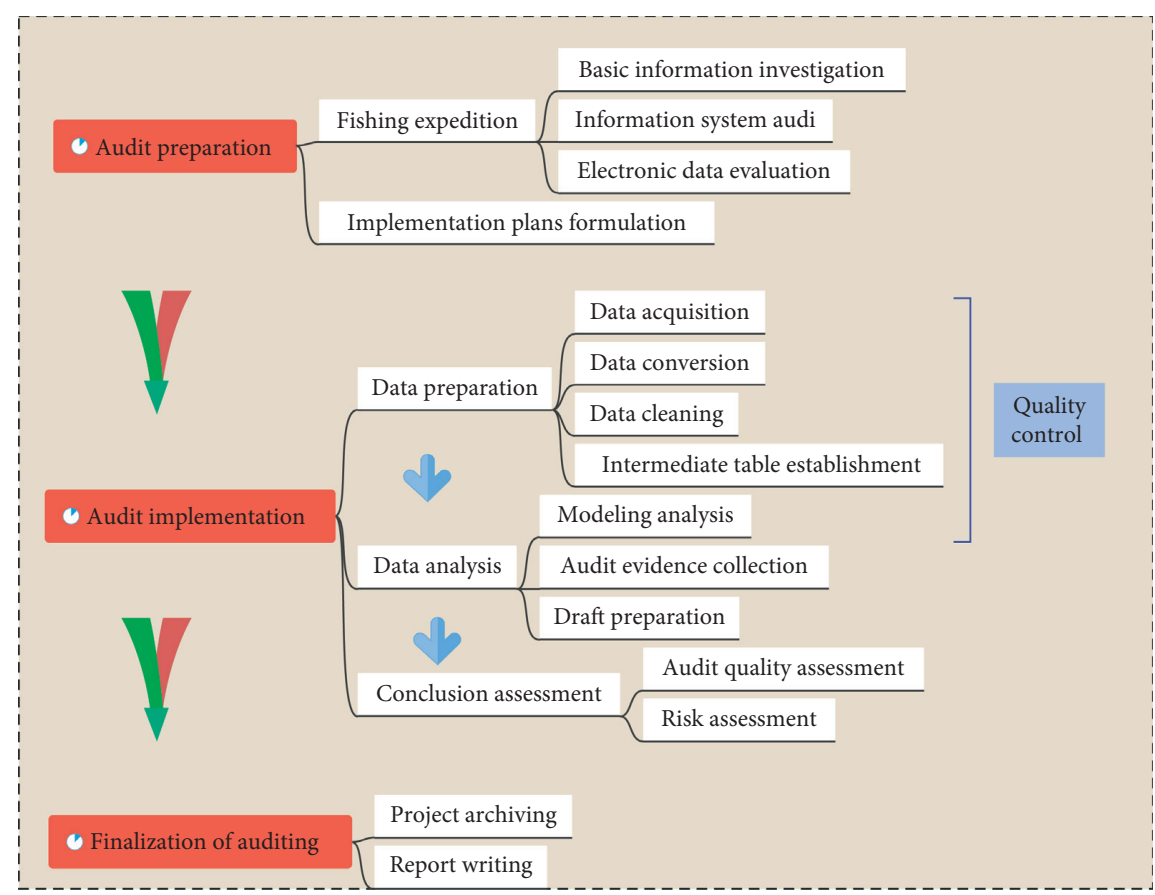

Figure 3: Flowchart of online audit.

constraint of accounting information quality, which reflects all the characteristics of accounting information to meet the requirements of regulations. Accounting information comes from the daily economic activities of the accounting entity. It is the economic information obtained through accounting by using accounting theories and methods for specific transactions or events. It is the product of all accounting activities of the accounting entity and is used to reflect the accounting entity's financial status and operating results and cash flow. As its result is to provide users of accounting information with accounting information related to their decision-making, as a product, accounting information needs to have a certain quality like ordinary products to meet the needs of information users. High-quality accounting information can meet the needs of accounting information users to the greatest extent. Therefore, the quality of 


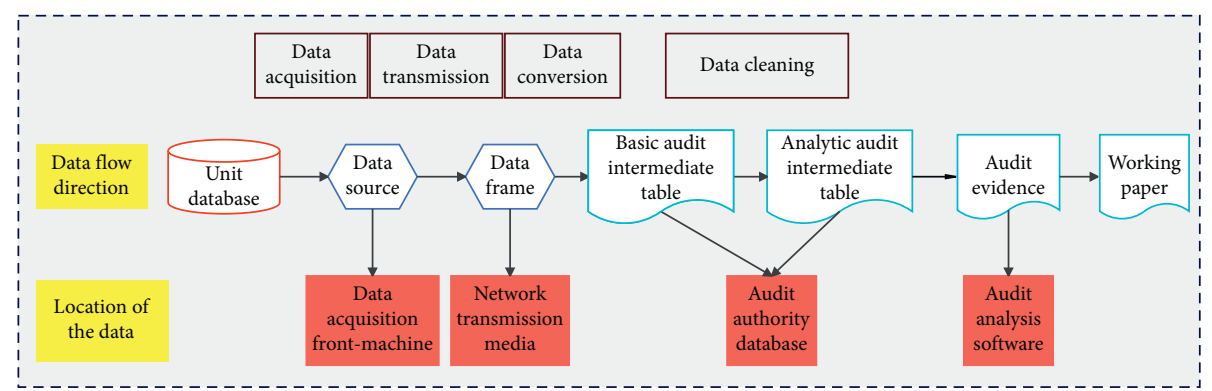

FIgURE 4: Data flowchart.

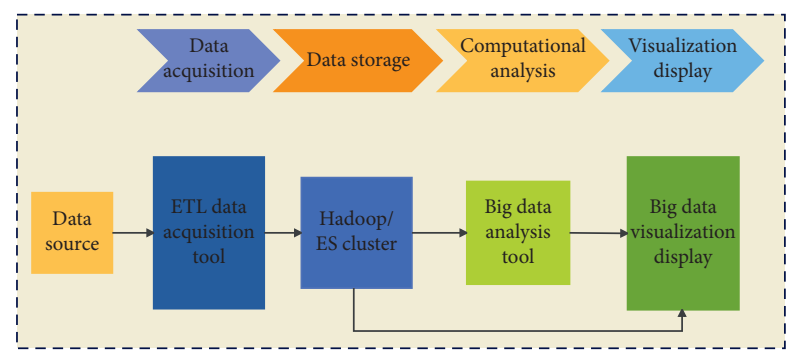

FIgURE 5: Schematic diagram of system processing flow.

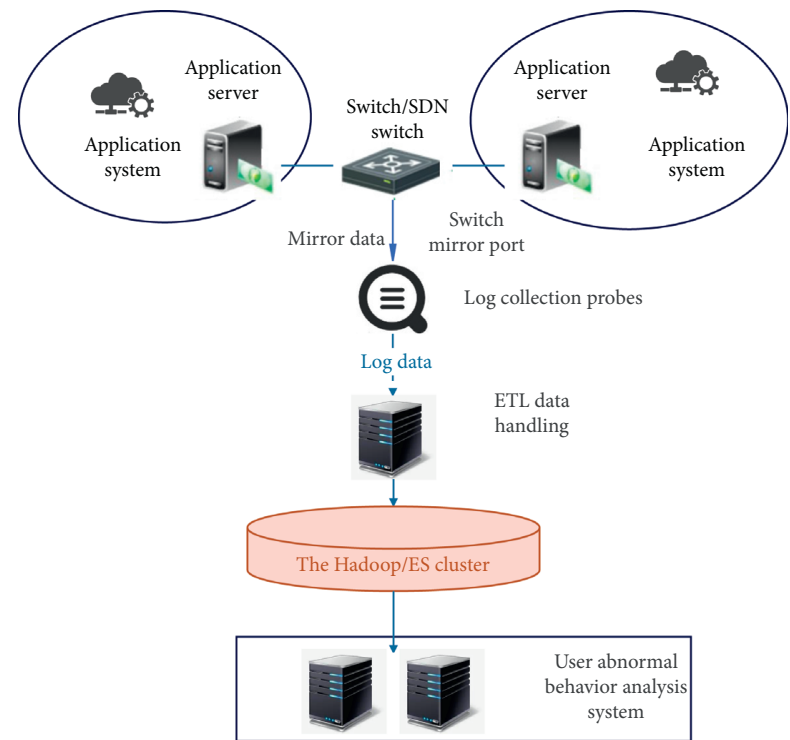

Figure 6: System deployment diagram.

accounting information is a prerequisite for accounting information to function and determines whether it is useful to information users. The connotation of the quality characteristics of accounting information is extremely rich, and the content of specific accounting information quality characteristics is different, and the degree of demand for accounting information of different accounting information users is also different. When the information demander makes a decision and the accounting information cannot meet the requirements at the same time, some of the information quality characteristics must be carefully selected to determine which quality characteristics should be given priority, and which quality characteristics can be reduced to the next or even ignored. Therefore, before forming the accounting information theory, we need to weigh the relationship between some major accounting information quality characteristics. From the perspective of the usefulness of decision-making or the view of fiduciary responsibility, which are the basic requirements for achieving useful goals in financial accounting decision-making. How to balance the relevance and reliability of accounting information is a topic that accounting standard-setting institutions and authoritative scholars pay close attention to. The relevance and reliability of accounting information are the basic requirements of accounting information users for accounting information. It can best reflect the internal requirements of financial accounting goals and has a significant impact on the choice of accounting methods and procedures by business operators. Therefore, it is necessary to ensure the reliability of the data and then analyze the data flow.

The quality of the collected raw data directly affects the success of the audit. Therefore, data collection is an important initial link in the networked audit model. From the data flow diagram (Figure 4), it can be seen that during the data collection stage, the data have changed twice, and the quality control should start from three control points.

The system processing flow is shown in Figure 5.

The system aggregates data through various mining algorithms and discovers abnormal patterns from various dimensions. On the basis of defining abnormal scenarios, assess whether an individual's operating behavior is normal or not in historical data, the degree of deviation, and the possible risks. Analysts can customize the model according to industry-specific custom rules to better fit the actual business environment of industry users and improve the accuracy of data mining. The final analysis results of the system are displayed in a visualized way of big data. The system deployment diagram is shown in Figure 6.

The user trust evaluation model based on log behavior is divided into two stages: the preprocessing stage and the log behavior trust evaluation stage. The basic structure of the analysis model is shown in Figure 7.

In the big data environment, when conducting data collection, auditors should make full use of the various technologies provided by the cloud platform and use cloud computing and big data functions in the audit business, and 


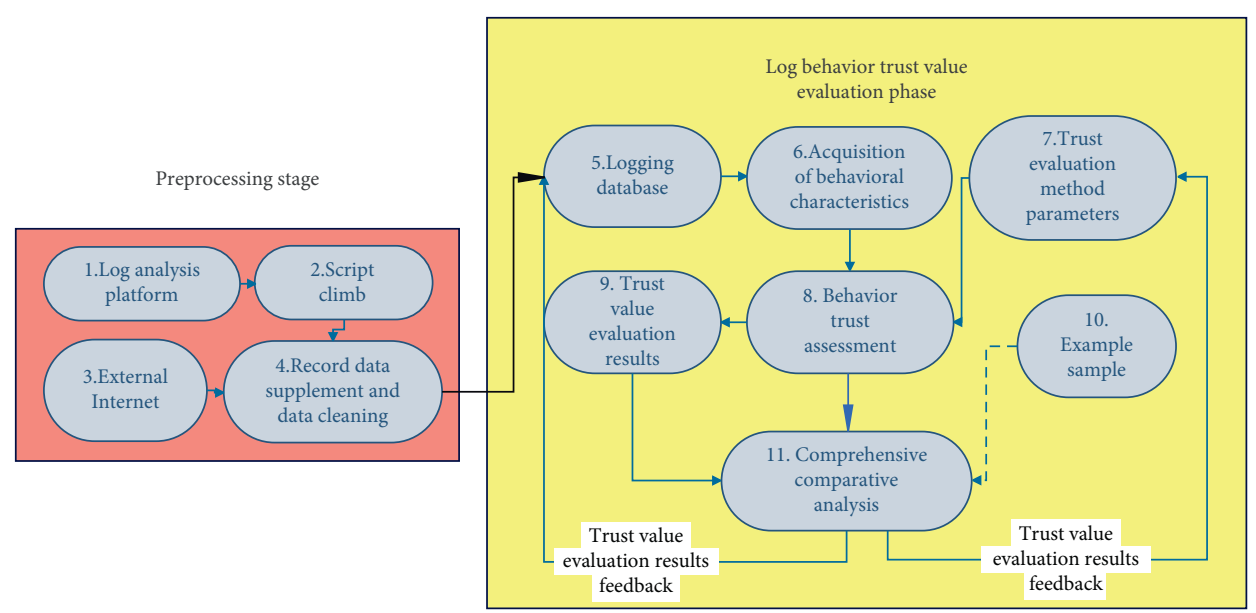

Figure 7: Flowchart of analysis model based on log behavior.

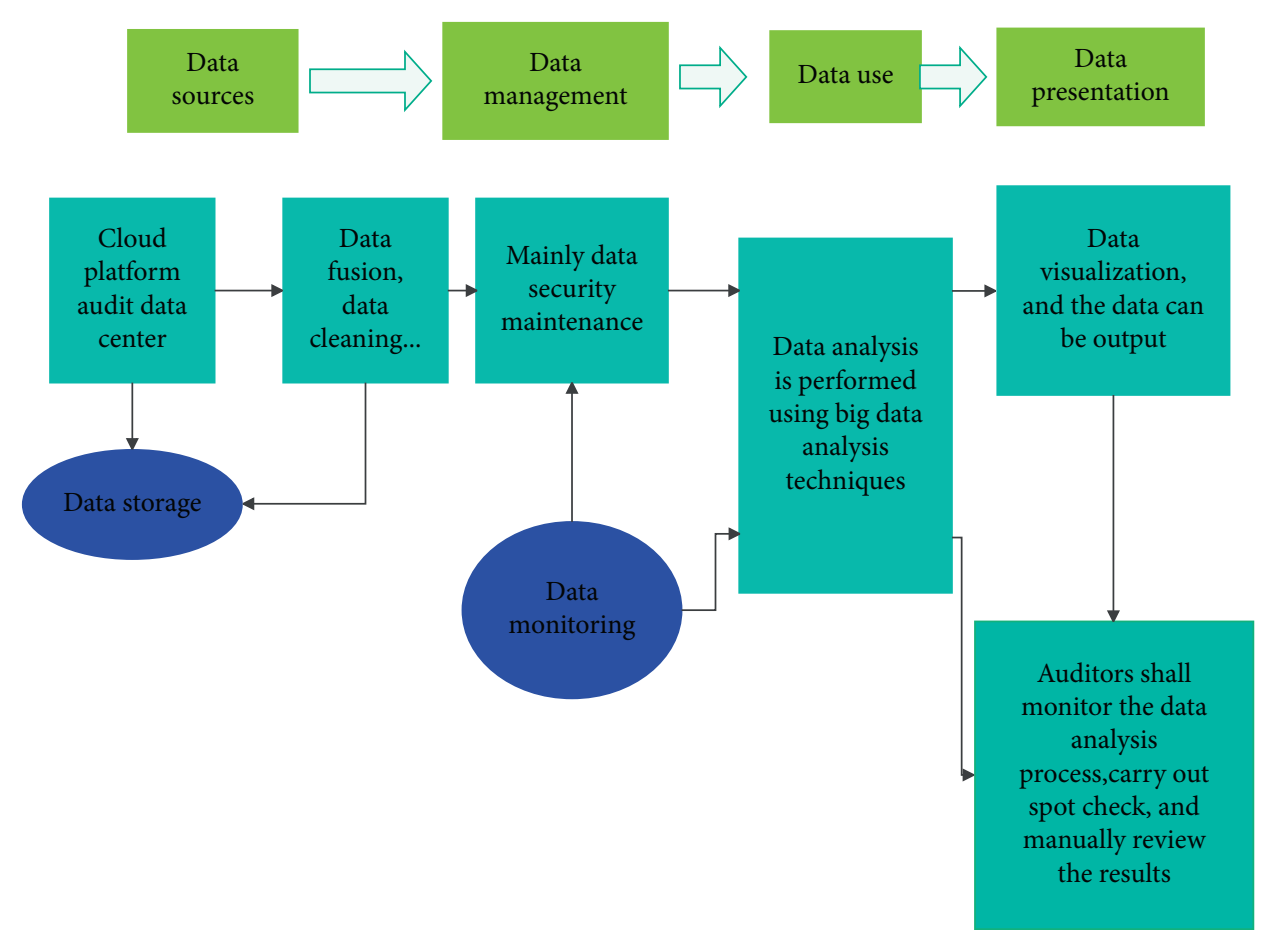

Figure 8: The flow of the data module.

the efficiency of the audit work will be greatly improved. Advanced computer technology and a large amount of data are integrated through overall planning, turning huge data resources into centralized and orderly audit data resources, which greatly improves the efficiency of fund use and the efficiency of data collection in audit work. Similarly, auditors working on a better data analysis platform can better lay the foundation for the next step. The data module process is shown in Figure 8.

After constructing the above model, the effect of the model is verified. The model constructed in this article can be used for mining and processing of accounting data, and the quality of accounting data can be evaluated with the support of the model. Therefore, this article mainly evaluates the mining effect of the algorithm and the effect of accounting data evaluation in the experimental research. Accounting data mining is shown in Table 1 and Figure 9.

With the support of the improved particle swarm algorithm, the accounting data mining effect of the system model in this paper is relatively ideal, and then, the accounting data evaluation effect evaluation is carried out, as shown in Table 2 and Figure 10.

From the above research, it can be seen that the accounting data quality evaluation system based on the improved particle swarm algorithm proposed in this article has a good accounting data quality evaluation effect and meets the basic needs of this article to build the system. 
TABLE 1: The effect of accounting data mining.

\begin{tabular}{lccc}
\hline NO & Data mining & NO & Data mining \\
\hline 1 & 94.28 & 16 & 94.21 \\
2 & 96.27 & 17 & 97.88 \\
3 & 94.25 & 18 & 94.76 \\
4 & 94.29 & 19 & 97.22 \\
5 & 94.88 & 20 & 95.78 \\
6 & 94.97 & 21 & 97.45 \\
7 & 94.62 & 22 & 95.26 \\
8 & 97.80 & 23 & 97.72 \\
9 & 97.07 & 24 & 95.86 \\
10 & 96.51 & 25 & 95.47 \\
11 & 95.45 & 26 & 94.35 \\
12 & 96.95 & 27 & 95.34 \\
13 & 96.50 & 28 & 95.01 \\
14 & 95.44 & 29 & 94.22 \\
15 & 97.37 & 30 & 95.30 \\
\hline
\end{tabular}

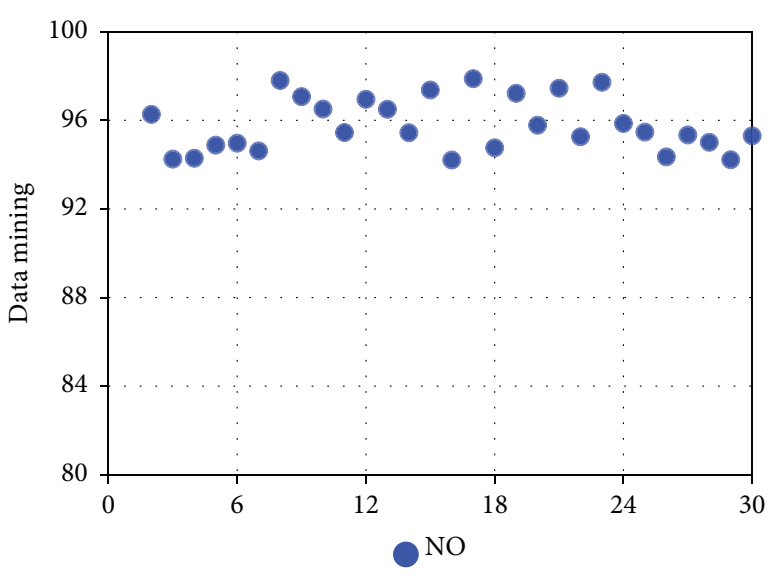

Figure 9: Statistical diagram of accounting data mining.

TABLE 2: The effect of accounting data quality evaluation.

\begin{tabular}{lccc}
\hline NO & Data evaluation & NO & Data evaluation \\
\hline 1 & 80.21 & 16 & 92.05 \\
2 & 91.69 & 17 & 83.59 \\
3 & 89.93 & 18 & 81.78 \\
4 & 88.58 & 19 & 91.69 \\
5 & 86.27 & 20 & 82.10 \\
6 & 90.31 & 21 & 91.23 \\
7 & 87.79 & 22 & 90.40 \\
8 & 81.75 & 23 & 86.42 \\
9 & 88.92 & 24 & 83.55 \\
10 & 92.12 & 25 & 86.75 \\
11 & 90.00 & 26 & 84.26 \\
12 & 80.76 & 27 & 90.25 \\
13 & 87.54 & 28 & 88.02 \\
14 & 90.04 & 29 & 80.18 \\
15 & 83.37 & 30 & 89.28 \\
\hline
\end{tabular}

\section{Conclusion}

Security accounting and auditing products basically use relational databases to store accounting and auditing data. Due to the limitations of relational databases, accounting

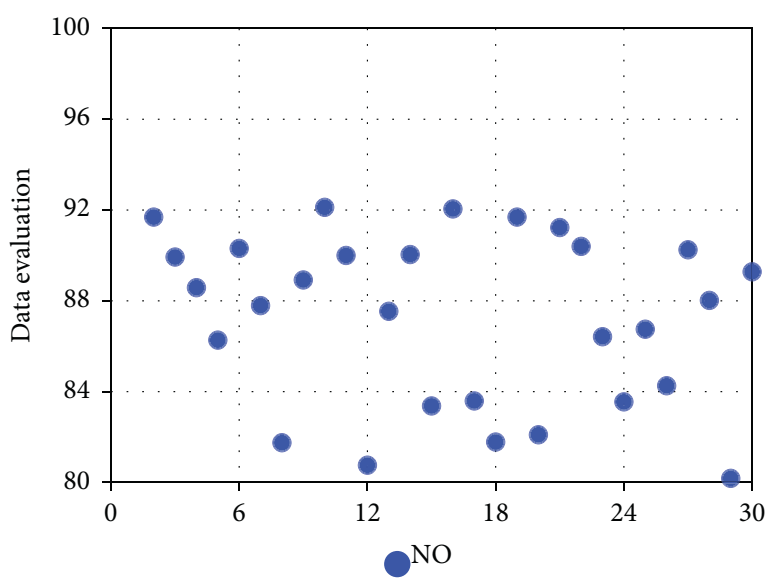

FIgURE 10: Statistical diagram of accounting data quality evaluation.

and auditing systems cannot store and process big data. With the continuous increase in log capacity, the speed of query statistics will become very slow, making it more difficult to carry out in-depth mining and analysis. Therefore, the storage capacity and processing capacity of the above products are very limited. In the current IT architecture, the number of devices and systems is very large, and the amount of data in logs and recording files generated every day is very large and has typical big data $4 \mathrm{~V}$ characteristics. Traditional security accounting audit products simply do not have the ability to store and process such a large amount of accounting audit log data based on the actual needs of accounting data quality assessment. This article combines the improved particle swarm algorithm to study the accounting data quality evaluation method, builds an intelligent analysis model based on the actual situation, and further improves the evaluation effect of accounting data quality on this basis.

\section{Data Availability}

The labeled dataset used to support the findings of this study is available from the corresponding author upon request.

\section{Conflicts of Interest}

The author declares no conflicts of interest.

\section{Acknowledgments}

This study was sponsored by Xinyang Vocational and Technical College Business School.

\section{References}

[1] K. S. Kumar, "Factors affecting the adoption of computerized accounting system (CAS) among smes in Jaffna District," SAARJ Journal on Banking \& Insurance Research, vol. 8, no. 6, pp. 11-15, 2019.

[2] B. L. Handoko, A. N. Mulyawan, J. Tanuwijaya, and F. Tanciady, "Big data in auditing for the future of data driven fraud detection," International Journal of Innovative 
Technology and Exploring Engineering, vol. 9, no. 3, pp. 2902-2907, 2020.

[3] Z. Rezaee, A. Dorestani, and S. Aliabadi, "Application of time series analyses in big data: practical, research, and education implications," Journal of Emerging Technologies in Accounting, vol. 15, no. 1, pp. 183-197, 2018.

[4] E. Huerta and S. Jensen, "An accounting information systems perspective on data analytics and Big Data," Journal of Information Systems, vol. 31, no. 3, pp. 101-114, 2017.

[5] S. Balne, "Analysis on research methods in bigdata applications," International Journal of Innovative Research in Computer and Communication Engineering, vol. 8, no. 10, pp. 4059-4063, 2020.

[6] P. B. De Laat, "Algorithmic decision-making based on machine learning from Big Data: can transparency restore accountability?" Philosophy \& Technology, vol. 31, no. 4, pp. 525-541, 2018.

[7] G. Tucker, "Sustainable product lifecycle management, industrial big data, and internet of things sensing networks in cyber-physical system-based smart factories," Journal of SelfGovernance and Management Economics, vol. 9, no. 1, pp. 9-19, 2021.

[8] P. B. de Laat, "Big data and algorithmic decision-making," ACM SIGCAS-Computers and Society, vol. 47, no. 3, pp. 3953, 2017.

[9] T. E. Marshall and S. L. Lambert, "Cloud-based intelligent accounting applications: accounting task automation using IBM watson cognitive computing," Journal of Emerging Technologies in Accounting, vol. 15, no. 1, pp. 199-215, 2018.

[10] D. Chessell and O. Neguriţă, "Smart industrial value creation, cyber-physical production networks, and real-time big data analytics in sustainable Internet of Things-based manufacturing systems," Journal of Self-Governance and Management Economics, vol. 8, no. 4, pp. 49-58, 2020.

[11] B. Abdualgalil and S. Abraham, "Efficient machine learning algorithms for knowledge discovery in big data: a literature review," Database, vol. 29, no. 5, pp. 3880-3889, 2020.

[12] O. Throne and G. Lăzăroiu, "Internet of Things-enabled sustainability, industrial big data analytics, and deep learningassisted smart process planning in cyber-physical manufacturing systems," Economics, Management, and Financial Markets, vol. 15, no. 4, pp. 49-58, 2020.

[13] E. Nica, C. I. Stan, A. G. Luan, and R. S. Oa, "Internet of things-based real-time production logistics, sustainable industrial value creation, and artificial intelligence-driven big data analytics in cyber-physical smart manufacturing systems," Economics, Management, and Financial Markets, vol. 16, no. 1, pp. 52-63, 2021.

[14] D. B. L. Shallal Almutairi, "Impact OF COVID19 ON accounting profession from the perspective OF a sample OF head OF accounting departments within KUWAITI manufacturing sector," Psychology and Education Journal, vol. 58, no. 2, pp. 4758-4768, 2021.

[15] V. Q. Thong, "Factors defining the effectiveness of integrated accounting information system in ERP environment-Evidence from Vietnam's enterprises," Economics and Business Administration, vol. 7, no. 2, pp. 96-110, 2017.

[16] J. R. A. Q. Al Natour, "The impact of information technology on the quality of accounting information (SFAC NO 8, 2010)," Turkish Journal of Computer and Mathematics Education (TURCOMAT), vol. 12, no. 13, pp. 885-903, 2021.

[17] A. P. Aaron, M. L. Kohlstrand, L. V. Welborn, and S. T. Curvey, "Maintaining medical record confidentiality and client privacy in the era of big data: ethical and legal responsibilities," Journal of the American Veterinary Medical Association, vol. 255, no. 3, pp. 282-288, 2019.

[18] B. J. Ali and M. S. Oudat, "Accounting information system And financial sustainability OF commercial and islamic banks: a review OF the literature," Journal of Management Information and Decision Sciences, vol. 24, no. 5, pp. 1-17, 2021.

[19] V. Brock and H. U. Khan, "Big data analytics: does organizational factor matters impact technology acceptance?" Journal of Big Data, vol. 4, no. 1, pp. 1-28, 2017.

[20] S. Antony Sibi and S. Antony Lucia Merin, "An investigation on accounting information system, Zambia," Shanlax International Journal of Management, vol. 8, no. 2, pp. 13-20, 2020.

[21] L. Loku, B. Fetaji, and A. Krsteski, "Automated medical data analyses of diseases using big data," Knowledge International Journal, vol. 28, no. 5, pp. 1719-1724, 2018. 